\title{
The Transmission of Monetary Shocks in a Multi-Region Economy: The Case of China
}

\author{
Yingyi Zhao ${ }^{1}$ \\ ${ }^{1}$ School of Economics and Management, Tsinghua University, Beijing, China \\ Correspondence: Yingyi Zhao, School of Economics and Management, Tsinghua University, Beijing, China. \\ E-mail: zhaoyyi@outlook.com
}

Received: January 27, 2019

Accepted: February 27, 2019

Online Published: March 29, 2019

doi:10.5539/ass.v15n4p1

URL: https://doi.org/10.5539/ass.v15n4p1

\begin{abstract}
This paper constructs a sticky price Dynamic Stochastic General Equilibrium model with multi-regions. Producers from different regions would range in price rigidity, production function, the regional structures of intermediate inputs. That is, firms from each area, can get intermediates and investments from all the regions in the country following the empirical Multi-region Input-Output table in China. Different from the previous symmetry model, the model in this paper allows idiosyncratic regional dynamics to the national monetary shocks. This model is calculated by the Bayesian estimation method using the regional and aggregate China empirical data.
\end{abstract}

Keywords: monetary shocks, multi-region economy, price rigidity, DSGE

\section{Introduction}

Economies would involve the consumption and production of goods which are produced by different producers in various regions with distinct productivities and inputs. While the network among areas in only partly acknowledged in Dynamic Stochastic General Equilibrium (DSGE) model, a favored tool of shocks analysis. Kim (2000) estimated a DSGE model with real and nominal rigidities in capturing nominal features of U.S. business cycles. Bouzkez, Cardia and Murcia (2005) used a sticky-price dynamic stochastic general equilibrium model with habit formation and capital adjustment costs to show the effects of monetary shocks in the US business cycle. However, Previous literature, listed above, is based on the symmetric economy model, which ignores the heterogeneity of goods and productivities across the country. However, some research results already show that there exists differentiation in price stickiness within regions in some developing country, like China. That heterogeneity is statistically important, and it is significant for the policy analysis. As a result, the simplified models cannot figure out some problems in policy analysis concerned about the trade and production network, such as why the monetary policy appears to have different effects in areas and how heterogeneity in price stickiness, I-O structure in production, investment interactions across areas affects the economy fluctuation.

In this paper, we build up a New Keynesian DSGE model where regions are heterogeneous in price stickiness, productive factors intensity and structure of input-output and investment. Within the country, there exists the representative household that makes decisions about consumption, supplying labor, and saving. Also, in each area, there is a continuum of monopolistically competitive producers to yield goods which are the same within the region. Producers in different areas make use of intermediate factors in heterogeneous intensities, intermediates and capital inputs following the macro data. According to the geographic division of the China Multi-region input-output table, this paper concentrates on eight broad areas, namely, Northeast, Jinjin, Northern Coast, Eastern Coast, Southern Coast, Middle area, Northwest and Southwest. Our Bayesian estimates indicate that price stickiness is the largest in the Northeast region and the least in the Eastern Coast. Impulse-response analysis shows that the regional effects of monetary shocks exhibit substantial heterogeneities across the region. The Northeast has the largest output growth rate, while the Eastern Coast has the least. Our results indicate that the heterogeneity on price rigidity, structures of input-output and investment, enlarges the mechanism of the multi-region model and brings the different feedback to the monetary disturbance.

The article is organized as follows. Section 2 presents a brief literature review related to the analysis of Monetary policy and shocks. Section 3 builds up the model within multi-regions. Section 4 describes the data, the 
estimation methodology, and the reported parameter. Section 5 gives the analysis of the result. Finally, Section 6 concludes.

\section{Review of Related Literature}

Monetary policy is based on the Keynesian theory that states that through making the monetary policy, the governments can influence macro-economic growth. In turn, this influence has been substantial increases in the national output, consumption, and inflation. There are considerable research works in the underlying theoretical frameworks used for policy analysis to examine the different aspects of monetary policy and to figure out its relationships to economic growth (Leeper, Sims, \& Zha, 1996; Bernanke, Gertler, \& Watson, 1997). Clarida, Gali and Gertler, (2000) estimated a forward-looking monetary policy reaction function for the postwar United States economy. Their results pointed to a significant difference in the monetary policy which was conducted pre and post- late 1979. Compared with the pre-Volcker period, the interest rate policy is more sensitive to the changes in the expected inflation during the Volcker-Greenspan period. Christiano, Eichenbaum and Evans, (2003) estimated a dynamic general equilibrium model with staggered wages and price contracts to investigate the dynamic response on inflation and aggregate variable to monetary shocks. The results showed that the monetary policy generated an inertial response in inflation and a persistent, hump-shaped response in output. Another key finding in that paper is that stickiness in nominal wages is crucial for the model's performance.

Recently some literature has constructed the DSGE model with heterogeneity. Carvalho (2006) introduces sector heterogeneity in price stickiness into a standard model to figure out how it affects the dynamics of monetary policy. Bouakez et al. (2009) built up a sticky price, DSGE model with heterogeneous production sectors to work out the transmission of monetary policy. The results suggest that price stickiness varies across sectors and the heterogeneity at the sectoral level can guide people through the macro and micro problems. Nakamura and Steinsson (2010) calibrated a multisector menu-cost model with intermediate inputs to estimated that aggregate nominal shocks can account for roughly $23 \%$ of U.S. business cycle.

\section{The Model and Mechanism}

The economy has the infinitely lived representative households, which are identical in each region, J distinct producers in each region, financial intermediary and government. It is heterogeneous in input parameters in the production function, price rigidity, and the regional network for intermediate inputs and investments.

\subsection{Households}

Households maximize utility from consuming a continuum of final goods varieties, holding money, having leisure, subject to budget constraints. We assume that the preferences and the budget constraints for the representative households in every area of the country are set up below:

The utility function for the representative household is,

$$
E_{t} \sum_{t=t}^{\infty} b^{t-t}\left[\log \left(C_{t}\right)+\log \left(1-N_{t}\right)+\frac{\left(M_{t} / P_{t}\right)^{1-e^{M}}}{1-e^{M}}\right]
$$

Where $\beta_{t}$ is discount factor, $C_{t}$ is the aggregate consumption goods, $N_{t}$ is the working hours, $M_{t}$ is the nominal money, $P_{t}$ is the aggregate consumer price index. On the assumption that the population growth rate is zero, the population size is constant and normalized to one.

The aggregate $C_{t}$ consists of goods from J regions,

$$
C_{t}=\left[\sum_{j=1}^{J}\left(x^{j}\right)^{1 / V^{C}}\left(c_{t}^{j}\right)^{\left(V^{C}-1\right) / V^{C}}\right]^{V^{C} /\left(V^{C}-1\right)}
$$

Where $c_{t}^{j}$ is the household's consumption of goods which are produced by region $\mathrm{j}$ and $\xi^{j}$ is the weight for the region $\mathrm{j}$ with the condition of $\sum \xi^{j}=1, \varsigma^{C}$ is the elasticity of substitution between the consumptions among the regions. In turn, $c_{t}^{j}$ is also thelaggregate over goods produced by all the firms in region $\mathrm{j}$,

$$
c_{t}^{j}=\left[\int_{0}^{l}\left(c_{t}^{j l}\right)^{(\theta-1) / \theta} d l\right]^{\theta /(\theta-l)}
$$

$c_{t}^{j l}$ is the household's consumption of good produced by firm 1 in region $\mathrm{j}$, and $\theta$ is the elasticity of substitution between the goods which are produced across the region. 
The labor supply is a combination of working hours which are provided to firms across region. That is,

$$
N_{t}=\left[\sum_{j=1}^{J}\left(n_{t}^{j}\right)^{\left(\varsigma^{N}+1\right) / \varsigma^{N}}\right]^{\varsigma^{N} /\left(\varsigma^{N}+1\right)}
$$

where $n_{t}^{j}$ is the labor supply for region $\mathrm{j}, \varsigma^{N}$ determines the elasticity of substitution between regional working hours. In addition, $n_{t}^{j}$ is the aggregate over working hours by all the firms $n_{t}^{j l}$, which is the labor supply, provided by firm 1 in region $\mathrm{j}$.

$$
n_{t}^{j}=\int_{0}^{l} n_{t}^{j l} d l
$$

The equation listed above suggests that the working hours in different firms in each region are perfect substitutions, but not perfect substitutions across the region. Hence, labor is perfectly mobile within the region but not the country.

The household's dynamic budget constraint is as follows,

$$
C_{t}+b_{t}+m_{t}+\sum_{j=1}^{J} \int_{0}^{1}\left(\frac{a_{t}^{j l} s_{t}^{j l}}{P_{t}}\right) d l \leq \sum_{j=1}^{J} \int_{0}^{1}\left(\frac{w_{t}^{l j} n_{t}^{l j}}{P_{t}}\right) d l+\frac{R_{t-1} b_{t-1}}{\pi_{t}}+\frac{m_{t-1}}{\pi_{t}}+\sum_{j=1}^{J} \int_{0}^{1}\left(\frac{\left(d_{t}^{j l}+a_{t}^{j l}\right) s_{t-1}^{j l}}{P_{t}}\right) d l+\frac{\Upsilon_{t}}{P_{t}}
$$

Where $b_{t}\left(B_{t} / P_{t}\right), m_{t}\left(M_{t} / P_{t}\right)$ are the real value of bond holding and the real money balance, separately. $s_{t}^{j l}$ is the shares in the mutual fund, and $a_{t}^{j l}, d_{t}^{j l}$ are the price and dividend payment of the share in the mutual fund. $\pi_{t}\left(P_{t} / P_{t-1}\right)$ presents the gross inflation rate of the country, $R_{t}$ is the gross nominal interest rate on the bonds, $\Upsilon_{t}$ is the government transfer to the household.

\subsection{Production Sector}

The firm 1 in each region $\mathrm{j}$ has the production function,

$$
y_{t}^{j l}=\left(z_{t}^{j} n_{t}^{j l}\right)^{v^{j}}\left(k_{t}^{j l}\right)^{\alpha^{j}}\left(H_{t}^{j l}\right)^{\gamma^{j}}
$$

Where $y_{t}^{j l}$ is the output for firm 1 in region $\mathrm{j}, z_{t}^{j}$ is a region-specific productivity index, $n_{t}^{j l}$ is labor demand, $k_{t}^{j l}$ is aggregate capital, $H_{t}^{j l}$ is aggregate material intermediates. The parameters of $v^{j}, \alpha^{j}$ and $\gamma^{j}$ are factor-input intensities with a constraint $v^{j}+\alpha^{j}+\gamma^{j}=1$.

The aggregate material intermediates are formed according to equation 8 ,

$$
H_{t}^{j l}=\left[\sum_{i=1}^{J}\left(\zeta_{i j}\right)^{1 / \varsigma^{H}}\left(h_{i, t}^{j l}\right)^{\left(\varsigma^{H}-1\right) / \varsigma^{H}}\right]^{\varsigma^{H} /\left(\varsigma^{H}-1\right)}
$$

Where $h_{i, t}^{j l}$ is the quantity of the intermediate goods produced by firms in region $\mathrm{i}$ and used by firm 1 in region $\mathrm{j}$. The aggregate of $h_{i, t}^{j l}, i \in(1, J), H_{t}^{j l}$ is the total material input for firm 1 in region $\mathrm{j}$. Besides, $h_{i, t}^{j l}$ is also the aggregate quantity of the whole firms in region $\mathrm{j}$, following equation 9

$$
h_{i, t}^{j l}=\left[\int_{0}^{1}\left(h_{i m, t}^{j l}\right)^{(\theta-1) / \theta} d m\right]^{\theta /(\theta-1)}
$$

Where $h_{i m, t}^{j l}$ is the inputs produced by firm $\mathrm{m}$ in region $\mathrm{i}$ and consumed by firm 1 in region $\mathrm{j}$.

For each firm across the region, the capital flow follows the law,

$$
k_{t+1}^{j l}=(1-\delta) k_{t}^{j l}+X_{t}^{j l}
$$

Where $\delta$ is the rate of depreciation, $X_{t}^{j l}$ is the aggregate investment which combines different goods produced by $\mathrm{J}$ regions within the country, $x_{i, t}^{j l}$ is the quantity of goods produced by region $\mathrm{i}$ and purchased by firm $1 \mathrm{in}$ region $\mathrm{j}$,

$$
X_{t}^{j l}=\prod_{i=1}^{J} \kappa_{i j}^{-\kappa_{j i}}\left(x_{i, t}^{j l}\right)^{\kappa_{j i}}
$$




$$
x_{i, t}^{j l}=\left[\int_{0}^{1}\left(x_{i m, t}^{j l}\right)^{(\theta-1) / \theta} d m\right]^{\theta /(\theta-1)}
$$

Where $x_{i m, t}^{j l}$ is the quantity of goods produced by firm $\mathrm{m}$ in region $\mathrm{i}$ and used by firm 1 in region $\mathrm{j}$.

$\zeta_{i j}$ and $\kappa_{i j}$ are the shares of intermediates and investment inputs, which are produced in region $\mathrm{i}$ and purchased by region $\mathrm{j}$, separately. These shares are empirically available and can be computed by using the data from China's multi-region Input-Output table.

Producer in each region would like to maximize its nominal profits, which finally would be transferred to shareholders in the form of dividend payment, according to equation 14.

$$
\begin{gathered}
E_{\tau} \sum_{t=\tau}^{\infty} \beta^{t-\tau}\left(\frac{\Lambda_{\tau}}{\Lambda_{t}}\right)\left(\frac{d_{t}^{j l}}{P_{t}}\right) \\
d_{t}^{j l}=\left(1-\Phi_{t}^{j l}\right) p_{t}^{j l}\left(c_{t}^{j l}+\sum_{i=1}^{J} \int_{0}^{1} x_{j l, t}^{i m} d m+\sum_{i=1}^{J} \int_{0}^{1} h_{j l, t}^{i m} d m\right)-R_{t}^{L} w_{t}^{j} t_{t}^{j l}-Q_{t}^{H^{j}} H_{t}^{j l}-\tau_{t} Q_{t}^{X^{j}}\left(X_{t}^{j l}+\Gamma_{t}^{j l}\right) \\
\Phi_{t}^{j l}=\Phi\left(p_{t}^{j l}, p_{t-1}^{j l}\right)=\frac{\phi^{j}}{2}\left(\frac{p_{t}^{j l}}{\pi_{s s} p_{t-1}^{j l}}-1\right)^{2}
\end{gathered}
$$

Where $\Phi_{t}^{j l}$ is a convex per-unit cost for changing the price for firms (Rotemberg,1982), $\phi^{j}$ is the parameter for adjustment cost, if $\phi^{j}$ is equal to zero, the prices of goods in region $\mathrm{j}$ are flexible and no changing cost, while $\phi^{j}$ is large, the price stickiness in region $\mathrm{j}$ is large. $\pi_{s s}$ is the rate of inflation in the steady state. $Q_{t}^{H^{\prime}}$ is the price of the composite intermediate goods $H_{t}^{j l}$, and $Q_{t}^{X^{j}}$ is the price of the composite investments $X_{t}^{j l}$.

\subsection{Financial Intermediary}

At time $t$, the perfectly competitive financial intermediary receives deposits from the households $B_{t}$, and at the same time, the intermediary also gives firms in each region a loan $L_{t}$, following the instrument law.

$$
L_{t}=\gamma^{B}\left(Y_{t}^{R} / Y_{s s}\right)^{\tau^{B}} B_{t}
$$

Where $\gamma^{B}$ is the loan-to-deposit ratio, $Y_{t}^{R}$ is the real GDP at time t, $Y_{s s}$ is the real GDP at the steady state, $\tau^{B}$ f 0 shows the procyclical characteristic of financial markets.

With the zero profit for the perfectly competitive financial intermediary, loan market clearing requires

$$
\left(R_{t}^{L}-1\right) l_{t}=\left(R_{t}-1\right) b_{t}
$$

\subsection{Monetary Policy}

Monetary policy is a dominant policy instrument in emerging market economies, especially for China. Burdekin and Siklos (2005) find that China should have followed the McCallum rule. However, Liu and Zhang (2007) claims that the McCallum rule cannot capture China's real money supply before 1997. There exists a huge difference between the estimated money supply with the real one. This paper follows the assumption of Zhang (2009) and employ the following monetary rule for China.

$$
\hat{\mu}_{t}=\rho_{\mu} \mu_{t-1}-\rho_{\pi} E_{t} \pi_{t+1}-\rho_{Y} \hat{Y}_{t}+\varepsilon_{t}^{\mu}
$$

Where $\varepsilon_{t}^{\mu}$ is assumed to be an $\operatorname{AR}(1)$ process

$$
\varepsilon_{t}^{\mu}=\rho_{\mu} \varepsilon_{t-1}^{\mu}+\lambda_{t}, \quad \lambda_{t}: N\left(0, \sigma_{\mu}^{2}\right)
$$

The government is the monetary authorities and supply the money according to $M_{t}=\mu_{t} M_{t-1}$. Where $\mu_{t}$ is the monetary growth rate at time t. $\hat{\mu}_{t}$ is the deviation of money growth rate from its HP trend. $\pi_{t}$ denotes inflation rate, $\hat{Y}_{t}$ is the output gap. $\lambda_{t}$ is the monetary policy shock. 


\subsection{Market Clear Condition}

Under the general equilibrium condition, households are identical, the total shareholdings in the mutual fund for each region add to one, and firms in each region are identical. Thus, $p_{t}^{j}=p_{t}^{j l}, c_{t}^{j}=c_{t}^{j l}, n_{t}^{j}=n_{t}^{j l}, B_{t}^{j}=B_{t}^{j l}$, $L_{t}^{j}=L_{t}^{j l}$. Where $p_{t}^{j}$ is the aggregate price in region $\mathrm{j}, p_{t}^{j l}$ is the price which is decided by firm 1 in region $\mathrm{j}$.

For region $\mathrm{j}$, we have the market clear condition;

$$
\frac{p_{t}^{j}}{P_{t}} y_{t}^{j}=\frac{p_{t}^{j}}{P_{t}}\left(c_{t}^{j}+\sum_{i=1}^{J} \int_{0}^{1} x_{j, t}^{m i} d m+\sum_{i=1}^{J} \int_{0}^{1} h_{j, t}^{m i} d m\right)
$$

Where $P_{t}$ is the aggregate price within the country and denotes to be the consumption price,

$$
P_{t}=\left[\sum_{j=1}^{J} \xi^{j}\left(p_{t}^{j}\right)^{1-\varsigma_{C}}\right]^{1 /\left(1-\varsigma_{C}\right)}
$$

For the country, the nominal GDP is $Y_{t} \equiv \sum_{j=1}^{J} Y_{t}^{j}$, and the real GDP is $Y_{t}^{R} \equiv Y_{t} / P_{t}$, where $Y_{t}^{j}$ is the nominal
output for region $\mathrm{j}, Y_{t}^{j} \equiv p_{t}^{j} y_{t}^{j}-Q_{t}^{H^{j}} H_{t}^{j}$.

\section{Empirical Analysis}

For the empirical analysis, this paper focuses on eight regions of China, namely, Northeast, Jinjin, Northern Coast, Eastern Coast, Southern Coast, Middle area, Northwest and South West. Northeast in China includes Jilin, Liaoning, and Harbin; Jinjin area includes Beijing and Tianjin; Northern Coast consists of Hebei and Shandong provinces; Eastern Coast area consists of Jiangsu, Shanghai, and Zhejiang; Southern Coast consists of Fujian, Guangdong, and Hainan; Middle area contains Shanxi, Henan, Anhui, Hubei, Hunan, Jiangxi; Northwest region contains Neimenggu, Shannxi, Ningxia, Gansu, Qinghai, Xinjiang; Southwest area involves Sichuan, Chongqing, Guangxi, Yunnan, Guizhou, Xizang. Those outputs aggregate to be China Gross Domestic Product (GDP). Focusing on these eight regions have three advantages. First, the eight regions are partitions of the China economy. Second, regions are closely related by the input and output network and have distinct heterogeneities in economic development. Finally, there are enough regional empirical data to identify the regional specific parameters.

\subsection{Parameter Estimates}

To calculate the steady state and the solution of the model, we should solve a large system of nonlinear equations at the same time. We cannot get the analytic solution, but the numerical solution with calculating in the iteration of the algorithm that optimizes the objection equation in our model. First, we should exploit various empirical data to calibrate the parameters in our model.

Our model in section 2 is estimated with Bayesian estimation method using key regional quarterly China time series from period 2005Q1 to 2014Q4 as observables: the log difference of real national GDP. All the data comes from The China National Bureau of Statistic, and with the method of HP filter, we get the data deviating from the HP trend.

First, we want to estimate the mode of the posterior distribution by maximizing the posterior function, with the prior information on the parameters and the empirical data. Second, the Markov Chain Monte Carlo method is used to get an accurate picture of the posterior distribution and to evaluate the model further.

The prior distributions on the stochastic processes are set as follows. The standard errors of the money shock's AR (1) processes are assumed to be an inverse-gamma distribution with a mean of 0.1 . The persistence is beta distributed with mean 0.5 and standard deviation 0.2 . The cost intensity for investment $\chi$ is assumed to be gamma distributed with mean 4 and standard deviation 4 . The same gamma distribution with mean 14 and standard deviation 10 is assumed for the price rigidity for each region. The loan-deposit ratio $\tau_{B}$ is gamma distribution with mean 1 and standard deviation 0.2.

Table 1 gives the mean and the $5 \%$ and $95 \%$ percentiles of the posterior distributions of the parameters. We know that the parameters of price rigidity $\phi^{j}$ for each region are not equal to zero. Because $\phi^{j}=0$ exhibits signs of the price flexibility, the result shows that price flexibility is not a rational setting in the multi-region model. Also, there exists significant heterogeneity in the price stickiness within eight regions. For example, compared to other regions, the parameter $\phi^{A}$ for Northeast is the largest, and the parameter $\phi^{D}$ for Eastern Coast region is the smallest. These results indicate that the less frequent price adjustments for Northeast than other regions, and 
more frequent price adjustments for Eastern Coast region.

The adjustment cost parameter $\chi$ for capital is measured to be 17.12, which is like estimations by Bouakez et al. (2009) using the U.S. data. Besides, the autoregressive coefficient of monetary shock is supposed to be 0.423 , and the standard deviation is 0.019 . These results imply that the monetary shock is continuous but has less volatility.

Table 1. Posterior Distribution of Some Parameters

\begin{tabular}{cccccc}
\hline Parameter & Mean & $10 \%$ HPD & Parameter & Mean & $10 \%$ HPD \\
\hline$\phi^{\text {Northeast }}$ & 39.28 & $(24.66,4.32)$ & $\phi^{\text {Sinjin }}$ & 28.10 & $(15.08,40.69)$ \\
$\phi^{\text {Northsea }}$ & 20.28 & $(13.17,27.54)$ & $\phi^{\text {EassSea }}$ & 10.76 & $(7.101,13.96)$ \\
$\phi^{\text {SouthSea }}$ & 16.66 & $(10.48,22.31)$ & $\phi^{\text {Middle }}$ & 21.26 & $(15.59,26.90)$ \\
$\phi^{\text {NorthWest }}$ & 37.70 & $(27.53,50.16)$ & $\phi^{\text {SouthWest }}$ & 29.40 & $(20.30,42.81)$ \\
$\rho_{\mu}$ & 0.423 & $(0.233,0.555)$ & $\sigma_{\mu}$ & 0.019 & $(0.016,0.022)$ \\
$\rho_{\pi}$ & 1.156 & $(0.904,1.431)$ & $\rho_{Y}$ & 0.226 & $(162,0.292)$ \\
$\chi$ & 17.12 & $(9.979,25.24)$ & $\tau_{B}$ & 0.528 & $(0.213,0.821)$ \\
\hline
\end{tabular}

Next, several parameters are fixed in the estimation procedure. The depreciation rate $\delta$ is 0.025 on a quarterly basis (Smets \& Wouters, 2007) and the subjective discount rate $\beta$ is fixed at 0.99 (Bouakez et al., 2009). In the literature about sticky-price model, the elasticity of substitution between goods from the different sector is estimated to value between 6 (Ireland, 2001) and 11(Barsky, House, \& Kimball, 2007). In our paper, we set the elasticity of substitution between goods from different regions to be 8 . The elasticities of money demand $\varepsilon^{M}$ and labor supply $\varsigma^{N}$ substitution are both supposed to be 1 . The elasticity of substitution between intermediates produced in different regions $\varsigma^{C}$ is 0.75 . The substitution elasticity of capital from different regions is assumed to be 0.75 . According to the empirical data from 2005-2014, the loan-deposit ratio in China should be 0.75 .

Under the assumption of equation 8 and 11, the intermediate input weights $\left\{\zeta_{i j}\right\}$ and capital input weights $\left\{\kappa_{i j}\right\}$ are equivalent to the part of region $\mathrm{i}$ in the intermediate input expenditures by the region $\mathrm{j}$. These proportions are calculated by using the data from the China Multi-region Input-Output table, which show how regions use the output from and sent the output to other regions to aggregate the national GDP. So, we use the 2012 China Multi-region I-O table to calculate these shares, the results are reported in Table 2.

Table 2. China Intermediates Input-Output Matrix 2012: Eight Regions

\begin{tabular}{ccccccccc}
\hline & NorEast & Jinjin & NorSea & EastSea & SouSea & Middle & NorWest & SouWest \\
\hline NorEast & 0.867 & 0.046 & 0.016 & 0.014 & 0.014 & 0.014 & 0.026 & 0.014 \\
Jinjin & 0.023 & 0.695 & 0.034 & 0.008 & 0.007 & 0.012 & 0.026 & 0.005 \\
NorSea & 0.023 & 0.112 & 0.862 & 0.017 & 0.014 & 0.039 & 0.048 & 0.011 \\
EastSea & 0.017 & 0.029 & 0.012 & 0.822 & 0.048 & 0.056 & 0.044 & 0.020 \\
SouSea & 0.023 & 0.027 & 0.012 & 0.021 & 0.809 & 0.033 & 0.044 & 0.070 \\
Middle & 0.018 & 0.045 & 0.036 & 0.074 & 0.048 & 0.801 & 0.061 & 0.028 \\
NorWest & 0.021 & 0.039 & 0.023 & 0.033 & 0.024 & 0.030 & 0.718 & 0.030 \\
SouWest & 0.008 & 0.008 & 0.006 & 0.011 & 0.035 & 0.013 & 0.033 & 0.822 \\
\hline
\end{tabular}

Table 2 reports the weight of total intermediate input that goes into downstream consuming region from the upstreaming production region. For example, $86.7 \%$ of intermediates used by Northeast goes into goods which are produced by Northeast, and Jinjin produces $2.3 \%$ of the intermediates. Each column in tabe 2 should be added up to one.

The capital input shares $\left\{\kappa_{i j}\right\}$ are also computed using the 2012 China Multi-region I-O table, which shows the structure of new investment within the eight regions. The capital input shares are reported in Table 3. 
Table 3. China New Investment Matrix 2012: Eight Regions

\begin{tabular}{ccccccccc}
\hline & NorEast & Jinjin & NorSea & EastSea & SouSea & Middle & NorWest & SouWest \\
\hline NorEast & 0.780 & 0.057 & 0.011 & 0.004 & 0.006 & 0.013 & 0.039 & 0.010 \\
Jinjin & 0.019 & 0.750 & 0.015 & 0.002 & 0.003 & 0.013 & 0.020 & 0.006 \\
NorSea & 0.008 & 0.015 & 0.825 & 0.001 & 0.002 & 0.023 & 0.014 & 0.007 \\
EastSea & 0.093 & 0.098 & 0.077 & 0.943 & 0.091 & 0.118 & 0.149 & 0.067 \\
SouSea & 0.033 & 0.011 & 0.011 & 0.009 & 0.853 & 0.041 & 0.050 & 0.094 \\
Middle & 0.023 & 0.024 & 0.032 & 0.029 & 0.022 & 0.744 & 0.048 & 0.025 \\
NorWest & 0.024 & 0.031 & 0.022 & 0.006 & 0.006 & 0.026 & 0.611 & 0.019 \\
SouWest & 0.020 & 0.014 & 0.007 & 0.005 & 0.017 & 0.021 & 0.070 & 0.773 \\
\hline
\end{tabular}

Table 3 shows the proportion of total investment by the consumption side coming from the production side. $78 \%$ of the investments, used by Northeast are the goods that are produced in the region of Northeast. Just like Table 2, each column should also be added up to one.

Besides, the parameters of the production function in each region are also estimated by the data on expenditure shares on investments, labor payments and intermediates from the 2012 China Multi-region I-O table. In the I-O table, data is available in 17 sectors in each region, so aggregating the sector up to achieve the regional level is straightforward. Then we get the data about intermediate and labor inputs across the eight regions at 2012. As we know, the Cobb-Douglas production function represents the relationship between the output and the combination of inputs, just labor inputs, intermediates, and capital inputs. Precisely $v^{j}, \gamma^{j}$ and $\gamma^{j}$ are the output elasticities of labor, intermediate and capital, and are equal to the proportion of total inputs in that outputs, separately. According to the equation 21,22, and 23, we have the input intensities for regional production functions.

$$
\begin{gathered}
v^{j}=\text { labor_input/total_output } \\
g^{j}=\text { intermediates_input / total_output } \\
v^{j}+\alpha^{j}+\gamma^{j}=1
\end{gathered}
$$

From the regional I-O table, the total consumptions for each region are also available. We can get the aggregate and the regional consumption levels and calculate the structure of household consumption for each region.

Table 4. The Production Function Parameters and Consumption Structure for Eight Regions, 2012

\begin{tabular}{ccccc}
\hline & Intermediates shares & Labor shares & Capital shares & Consumption share \\
\hline NorEast & 0.637 & 0.157 & 0.206 & 0.083 \\
Jinjin & 0.635 & 0.167 & 0.198 & 0.046 \\
NorSea & 0.690 & 0.126 & 0.184 & 0.117 \\
EastSea & 0.669 & 0.139 & 0.192 & 0.186 \\
SouSea & 0.621 & 0.188 & 0.191 & 0.146 \\
Middle & 0.637 & 0.169 & 0.194 & 0.211 \\
NorWest & 0.588 & 0.196 & 0.216 & 0.074 \\
SouWest & 0.599 & 0.202 & 0.198 & 0.137 \\
\hline
\end{tabular}

The regional structure concerning intermediates, labor and capital and consumption are, respectively, listed above. For example, output elasticities with respect to intermediates, labor, and capital, in region Northeast, are, respectively, assumed to be $0.637,0.157$ and 0.206 . Within the eight regions, Northern Coast region has the highest output elasticity of intermediates and Southwest has the highest output elasticity of labor. To be a surprise, Northwest has the highest output elasticity of capital within the country. Regarding consumption, the 
structure is not even across regions. The proportion in Middle area is larger than others with 21.1, and Jinjin area has the least portion for consumption.

\section{Reactions to a Monetary Policy Shock}

From the steady state, the multi-region economy bears an unexpected and positive shock in the monetary supply growth rate (one-standard deviation increases in $\lambda_{t}$ ). Notice that all the variables are reported as annualized quarterly rates and the quantities are reported as log-level deviations from the stead state. Figure 1 plots the impose response of aggregate and regional variables following the monetary shocks。
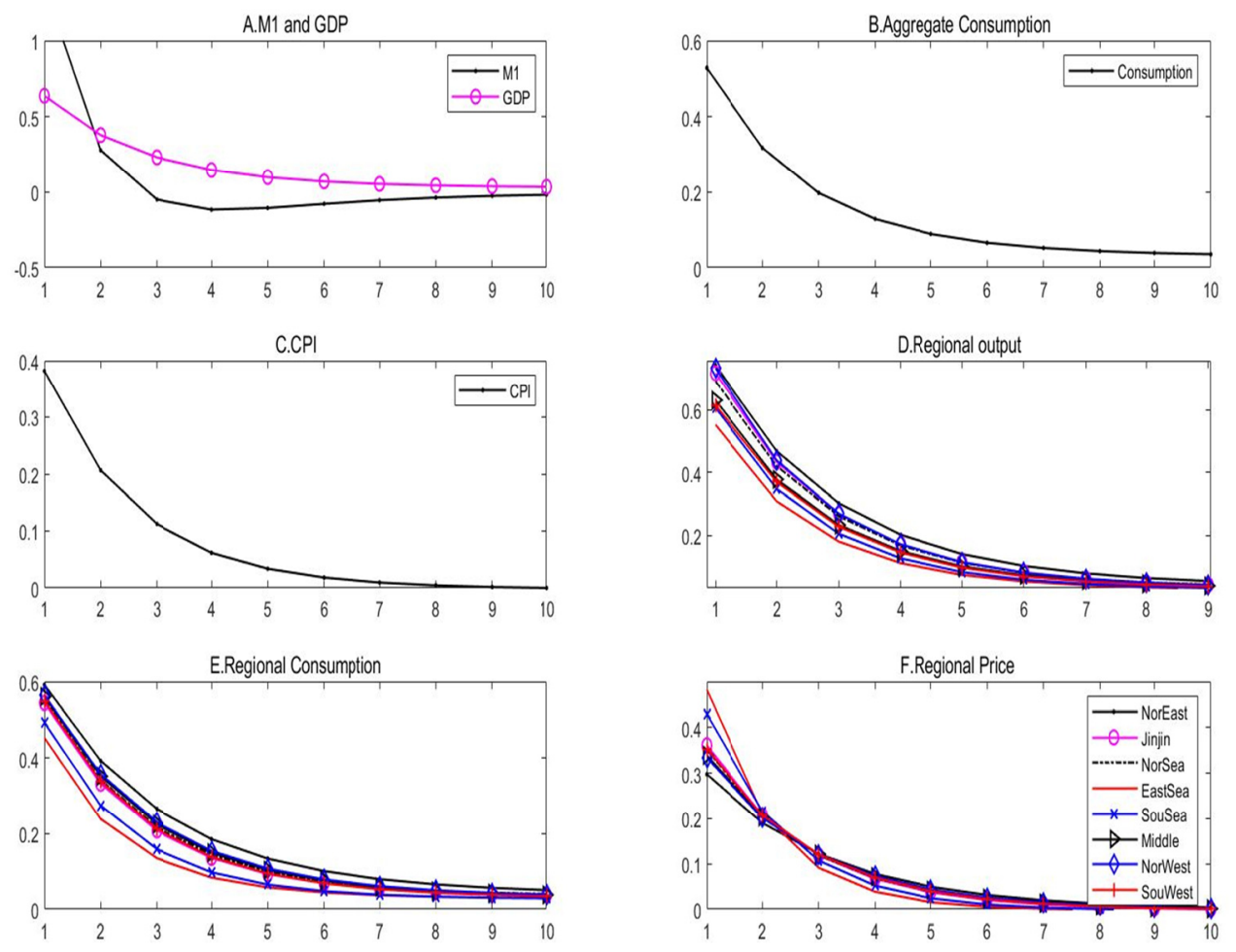

Figure 1. Reactions to a Monetary Policy Shock

The effects of the aggregate variables are well in line with the literature that has used the symmetric DSGE model to study the effects of monetary policy shocks.

Panel $\mathrm{C}$ and $\mathrm{F}$ show the responses of national consumer price index (CPI) and regional inflation t. All of the aggregate and regional inflation rates increase, but the increase is not even. The increase in regions which have more-frequent price adjustments would be more pronounced, like Eastern coast, Southern coast. However, the increase in regions, like Northeast and Northwest, would be less than other regions.

Positive monetary shocks also lead to increases in aggregate and regional consumptions (Panel B and E). The results show that the largest increases in the consumption of Northeast and Northwest, and the least in Southern coast and Eastern Coast. To figure out these uneven changes, we combine the change of relative price with the consumption. Then it is relatively apparent that the order of increases in consumption is almost to be the opposite of the relative price. The largest increase in the regional household consumption is the smallest for goods produced in the region which has the less frequent price adjustments.

Panel A and D show that the regional output which is subjected to an unexpected rise in the monetary growth rate, increase significantly. The monetary shock also leads to increases in aggregate and regional consumptions, starting at the original steady state position, the growth of the aggregate output increase to $0.6 \%$, with the largest in the region of Northeast, Southwest, and least of Eastern coast and Southern coast (Panel E). As one would expect, the greater the price increase, the smaller the output increase, however, different from the regional 
consumption, because of the intermediates I-O and investments network, the increasing order of the regional output is not the same as the order of the price. Firm increases in output for intermediates and investment to satisfy the demand for firms in other regions, so their output also increases as a response to the increasing input demand for other regions.

\section{Conclusion}

This article demonstrates the effects of monetary policy through a sticky price DSGE multi-region model. Compared with those previous models only with one region, this article explicitly incorporates heterogeneity in intermediated input and investment structure. The results show that modeling realistically the input-output structures of the economy is significant to figure out the transmission mechanism of the monetary policy. For example, using this model, we can demonstrate how the monetary policy shock influences the price index, consumption. What's more important, with the consideration of the I-O structures and the heterogeneity of price rigidness, we can explain the reason why some regions are more sensitive to monetary policy than others even.

Though the method of Bayesian estimation, econometric results demonstrate that price stickiness is statistically different across the regions in China. East coast area accounts for most of the flexibility, and Northeast account for most of the stickiness in price. Then the monetary policy should lie in pertinence and be more effective with less inflation.

\section{References}

Adolfson, M., Laséen, S., Lindé, J., \& Villani, M. (2007). Bayesian estimation of an open economy DSGE model with incomplete pass-through. Journal of International Economics, 72(2), 481-511. https://doi.org/10.1016/j.jinteco.2007.01.003

Barsky, R. B., House, C. L., \& Kimball, M. S. (2007). Sticky-price models and durable goods. American Economic Review, 97(3), 984-998. https://doi.org/10.1257/aer.97.3.984

Bernanke, B. S., Gertler, M., Watson, M., Sims, C. A., \& Friedman, B. M. (1997). Systematic monetary policy and the effects of oil price shocks. Brookings papers on economic activity, (1), 91-157. https://doi.org/10.2307/2534702

Bouakez, H., Cardia, E., \& Ruge-Murcia, F. J. (2005). Habit formation and the persistence of monetary shocks. Journal of Monetary Economics, 52(6), 1073-1088. https://doi.org/10.1016/j.jmoneco.2005.08.009

Bouakez, H., Cardia, E., \& Ruge-Murcia, F. J. (2009). The transmission of monetary policy in a multisector economy. International Economic Review, 50(4), 1243-1266. https://doi.org/10.1111/j.1468-2354.2009. 00567.x

Burdekin, R. C., \& Siklos, P. L. (2008). What has driven Chinese monetary policy since 1990? Investigating the People's bank's policy rule. Journal of International Money and Finance, 27(5), 847-859. https://doi.org/10.1016/j.jimonfin.2008.04.006

Carvalho, C. (2006). Heterogeneity in price stickiness and the real effects of monetary shocks. Frontiers in Macroeconomics, 6(3). https://doi.org/10.2202/1534-6021.1320

Christiano, L. J., Eichenbaum, M., \& Evans, C. L. (2005). Nominal rigidities and the dynamic effects of a shock to monetary policy. Journal of political Economy, 113(1), 1-45. https://doi.org/10.3386/w8403

Clarida, R., Gali, J., \& Gertler, M. (2000). Monetary policy rules and macroeconomic stability: Evidence and some theory. The Quarterly journal of economics, 115(1), 147-180. https://doi.org/10.3386/w6442

Dedola, L., \& Lippi, F. (2005). The monetary transmission mechanism: Evidence from the industries of five OECD countries. European Economic Review, 49(6), 1543-1569. https://doi.org/10.1016/j.euroecorev.2003. 11.006

Galí, J., \& Rabanal, P. (2004). Technology shocks and aggregate fluctuations: How well does the real business cycle model fit postwar US data? NBER macroeconomics annual, 19, 225-288. https://doi.org/10.1086/ma. 19.3585339

Genesove, D. (2003). The nominal rigidity of apartment rents. Review of Economics and Statistics, 85(4), 844-853. https://doi.org/10.1162/003465303772815763

Groth, C. (2008). Quantifying UK capital adjustment costs. Economica, 75(298), 310-325. https://doi.org/10.1111/j.1468-0335.2007.00622.x

Ireland, P. N. (2001). Sticky-price models of the business cycle: Specification and stability. Journal of Monetary 
Economics, 47(1), 3-18. https://doi.org/10.1016/s0304-3932(00)00047-7

Kim, J. (2000). Constructing and estimating a realistic optimizing model of monetary policy. Journal of Monetary Economics, 45(2), 329-359. https://doi.org/10.1016/s0304-3932(99)00054-9

Leeper, E. M., Sims, C. A., Zha, T., Hall, R. E., \& Bernanke, B. S. (1996). What does monetary policy do? Brookings papers on economic activity, (2), 1-78. https://doi.org/10.2307/2534619

Liu, L., \& Zhang, W. (2007). A Model Based Approach to Monetary Policy Analysis for China. Hong Kong Monetary Authority Working Paper, 18. https://doi.org/10.12735/jfe.v5n2p39

Nakamura, E., \& Steinsson, J. (2010). Monetary non-neutrality in a multisector menu cost model. The Quarterly Journal of Economics, 125(3), 961-1013. https://doi.org/10.3386/w14001

Rotemberg, J. J. (1982). Sticky prices in the United States. Journal of Political Economy, 90(6), 1187-1211. https://doi.org/10.1086/261117

Smets, F., \& Wouters, R. (2007). Shocks and frictions in US business cycles: A Bayesian DSGE approach. American economic review, 97(3), 586-606. https://doi.org/10.2139/ssrn.1687574

Zhang, W. (2009). China's monetary policy: Quantity versus price rules. Journal of Macroeconomics, 31(3), 473-484. https://doi.org/10.1016/j.jmacro.2008.09.003

\section{Copyrights}

Copyright for this article is retained by the author(s), with first publication rights granted to the journal.

This is an open-access article distributed under the terms and conditions of the Creative Commons Attribution license (http://creativecommons.org/licenses/by/4.0/). 